\title{
Maternal Nutrient Intake and Risks for Transverse and Longitudinal Limb Deficiencies: Data from the National Birth Defects Prevention Study, 1997-2003
}

\author{
Julie Robitaille, ${ }^{1,2}$ Suzan L. Carmichael, ${ }^{3}$ Gary M. Shaw, ${ }^{3}$ Richard S. Olney, ${ }^{1 *}$ and The National Birth \\ Defects Prevention Study \\ ${ }^{1}$ National Center on Birth Defects and Developmental Disabilities, Centers for Disease Control and Prevention, Atlanta, Georgia \\ ${ }^{2}$ Department of Food Science and Nutrition, Laval University, Quebec City, Quebec, Canada \\ ${ }^{3}$ March of Dimes Foundation, California Research Division, Oakland, California \\ Received 3 December 2008; Revised 27 February 2009; Accepted 1 March 2009
}

\begin{abstract}
BACKGROUND: The association between periconceptional intake of supplements containing folic acid with specific subtypes of limb deficiencies has been inconsistent. The objective was to investigate whether intake of nutrients involved in one-carbon metabolism (folate, vitamin $B_{6}$, vitamin $B_{12}$, riboflavin, choline, betaine, zinc, and methionine) through diet alone or in combination with a supplement containing folic acid influenced the risk for transverse limb deficiency (TLD) and longitudinal limb deficiency (LLD). METHODS: We analyzed 1997-2003 data from the National Birth Defects Prevention Study and included 324 case infants with TLD, 158 case infants with LLD, and 4982 nonmalformed control infants. A food frequency questionnaire was used to estimate nutrient intakes. Use of supplements containing folic acid 1 month before through 2 months after conception was recorded. RESULTS: Use of a supplement containing folic acid was not associated with LLD or TLD. For nonsupplement users, within (1) the lowest quartile of dietary folate intake or vitamin $\mathrm{B}_{6}$ intake, adjusted odds ratios (aORs) for LLD were, respectively, 3.86 (95\% confidence interval [CI]: 1.08-13.78) and 4.36 (95\% CI: 0.93-20.48); and (2) the lowest quartile for riboflavin intake, the aOR for TLD was 2.94 (95\% CI: 1.04-8.32). For supplement users within the lowest quartile of folate intake or riboflavin intake, the aORs for TLD were, respectively, 1.52 (95\% CI: $0.91-2.54)$ and 1.54 (95\% CI: 1.00 2.37). CONCLUSIONS: TLD and LLD were not associated with supplement use, but TLD was associated with low intakes of riboflavin from diet. Birth Defects Research (Part A) 85:773-779, 2009. (C) 2009 Wiley-Liss, Inc.
\end{abstract}

Key words: congenital; limb deficiencies; riboflavin; folic acid; vitamin $\mathrm{B}_{6}$

\section{INTRODUCTION}

Limb deficiencies are relatively common birth defects, occurring among approximately 1 in 2000 newborn infants. The etiology of limb deficiency remains largely unknown, but previous studies suggest that factors leading to vascular disruption (such as arterial occlusion or exposure to some teratogens) are related to certain types of limb deficiency (Graham et al., 1980; Hoyme et al., 1982; Van Allen et al., 1982; Webster et al., 1987; Van Allen et al., 1992; Holmes, 2002). Pregestational maternal diabetes has been associated with limb deficiency (Van Allen et al., 1989; Aberg et al., 2001; Correa et al., 2008). Maternal obesity also has been studied as a potential cause for limb deficiency (Moore et al., 2000; Shaw et al., 2000; Watkins et al., 2003; Waller et al., 2007). Although most studies have found no associations (Moore et al., 2000; Shaw et al., 2000; Watkins et al., 2003), Waller et al.
(2007) observed an increased risk for limb deficiencies among obese mothers.

Periconceptional intake of supplements containing folic acid has been associated with reductions in the risk for limb deficiencies (Czeizel, 1993; Shaw et al., 1995; Yang et al., 1997; Werler et al., 1999). However, the association

Presented at the 48th Annual Meeting of the Teratology Society, Monterey, CA, June 28-July 2, 2008.

The findings and conclusions in this report are those of the authors and do not necessarily represent the official position of the Centers for Disease Control and Prevention or the California Department of Public Health.

*Correspondence to: Richard S. Olney, MD, MPH, National Center on Birth Defects and Developmental Disabilities, Centers for Disease Control and Prevention, 1600 Clifton Road, MS E-86, Atlanta, GA 30333. E-mail: rolney@cdc.gov Published online 6 April 2009 in Wiley InterScience (www.interscience. wiley.com).

DOI: $10.1002 /$ bdra.20587 
with specific subtypes of limb deficiencies has been inconsistent, potentially because of small numbers of cases and different methods of case classification (Shaw et al., 1995; Yang et al., 1997). Additionally, altered folate and homocysteine metabolism has been suggested as a risk factor for transverse terminal limb deficiencies (Hunter, 2000; Shashi et al., 2001). These findings suggest that impairment of the folate-mediated, one-carbon metabolic pathway resulting from inadequate intakes of folate and other nutrients in this pathway (vitamin $B_{6}$, vitamin $\mathrm{B}_{12}$, riboflavin, betaine, choline, zinc, and methionine) during fetal development could play an important role in the risks for limb deficiencies. However, the association of limb deficiencies with specific nutrients involved in one-carbon metabolism has not been well explored. We conducted the current study to address these issues.

This study investigated the association of maternal intake of nutrients involved in one-carbon metabolism with longitudinal limb deficiency (LLD) and with transverse limb deficiency (TLD). Specifically, we investigated whether maternal intake of folic acid-containing supplements and dietary intake of folate, vitamin $B_{6}$, vitamin $\mathrm{B}_{12}$, riboflavin, betaine, choline, zinc, and methionine is associated with LLD and TLD.

\section{METHODS Subjects}

Data were obtained from the National Birth Defects Prevention Study (NBDPS), a multistate case-control study of more than 30 different birth defects. We included data on deliveries that had estimated due dates from October 1997 through December 2003. Detailed study methods and descriptions of the surveillance systems in the states that contributed data have been published elsewhere (Yoon et al., 2001). Briefly, liveborn and stillborn infants with limb deficiencies and other structural defects were identified through population-based birth defects surveillance programs in each participating state (Arkansas, California, Georgia, Iowa, Massachusetts, North Carolina, New Jersey, New York, Texas, and Utah). Seven states (Arkansas, California, Georgia, Iowa, North Carolina, Texas, and Utah) also included defects that were prenatally diagnosed and resulted in elective terminations. Control infants included liveborn infants without birth defects randomly selected using data from birth certificates (Arkansas [2000-2003], Georgia [20012003], Iowa, Massachusetts, North Carolina, New Jersey, and Utah) or from birth hospitals (Arkansas [1997-1999], California, Georgia [1997-2000], New York, and Texas). Infants with recognized or strongly suspected single-gene disorders or chromosome abnormalities were excluded from the NBDPS. This study is an approved activity of the institutional review boards of the participating study centers and the Centers for Disease Control and Prevention.

\section{Case Definition}

To determine eligibility for the maternal interview, clinical geneticists in each state reviewed abstracted records of physical examinations, radiographs, laboratory investigations, autopsies, surgical reports, and other relevant medical information. In addition, NBDPS records of limb deficiencies were reviewed independently by a clini- cal geneticist (R.S.O.) for inclusion in this analysis. Infants with absent, partially absent, or missing bony elements of the extremities were included. The TLD classification included limbs with absent distal segments and intact proximal structures, such as digital deficiencies with absent phalanges and intact metacarpal or metatarsal bones, without identified single-gene mutations or clinical histories suggestive of a Mendelian disorder. The LLD category included preaxial or postaxial ray deficiencies, such as absent thumbs with or without radial deficiencies, without identified single-gene mutations or clinical histories suggestive of a Mendelian disorder. Infants with evidence of amnion rupture sequence or central axis deficiencies (split hand/split foot) were excluded. We also excluded infants whose mothers said they had diabetes before they were pregnant. Based on these criteria, 158 case infants with LLD, 324 case infants with TLD, and 4982 control infants were included in the analysis. Among those with LLD, 81 were isolated and 77 had multiple, unrelated defects; whereas among those with TLD, 275 were isolated and 48 were "multiple" cases.

\section{Maternal Interview}

Maternal interviews were conducted by telephone using a standardized computer-based interview from 6 weeks through 24 months after delivery. Participation rates for the interviews were $72 \%$ among case mothers of infants with limb deficiencies and $67 \%$ among control mothers. These interviews compiled data on family, health, occupation(s), lifestyle, tobacco smoking, alcohol drinking, and exposures to chemicals and drugs. Maternal nutrient intake information was obtained from a shortened version of the Willett Food Frequency Questionnaire assessed during the interview (Willett et al., 1987). The questionnaire collected frequency of intake information for 58 food items during the year before pregnancy. The U.S. Department of Agriculture (USDA) version SR19 nutrient database was used for nutrient calculations (USDA Agricultural Research Service, 2006). The database is relatively complete for all of the studied nutrients, with the exceptions of choline and betaine. For choline and betaine, we used recently released databases from the USDA that were more complete; that is, we used the USDA choline database as our primary source of information, and we used the USDA version 20 as a secondary source (USDA Agricultural Research Service, 2007, 2008). Periconceptional intake of supplements containing folic acid was defined as reporting intake of any multivitamins or prenatal products that contained folic acid or single vitamins labeled as folic acid any time from 1 month before through 2 months after conception. Briefly, women were asked about their intake of vitamin and mineral dietary supplements during the 12 weeks before conception through the date of delivery. Participants reported start and stop dates and frequency of intake for each product, and women who did not know the exact start or stop dates of intake reported the duration of intake. All products were reviewed to assess their content of folic acid and included the categories: prenatal multivitamin or mineral supplements, nonprenatal multivitamin or mineral supplements, and other folic acidcontaining supplements. 
Table 1

Demographic and Socioeconomic Characteristics (National Birth Defects Prevention Study, 1997-2003)

\begin{tabular}{|c|c|c|c|}
\hline Characteristic & $\begin{array}{l}\text { Control } \\
\text { infants } \\
\text { N (\%) }\end{array}$ & $\begin{array}{c}\text { Longitudinal } \\
\text { limb defects } \\
\mathrm{N}(\%)\end{array}$ & $\begin{array}{c}\text { Transverse } \\
\text { limb defects } \\
\text { N }(\%)\end{array}$ \\
\hline \multicolumn{4}{|l|}{ Child sex } \\
\hline Male & 2518 (50.6) & $116(56.6)$ & $171(53.1)$ \\
\hline Female & 2459 (49.4) & $89(43.4)$ & $151(46.9)$ \\
\hline \multicolumn{4}{|l|}{ Maternal race or ethnicity } \\
\hline Non-Hispanic White & $2993(60.2)$ & $116(55.8)$ & $180(55.7)$ \\
\hline $\begin{array}{l}\text { Non-Hispanic, Black, or } \\
\text { African American }\end{array}$ & $583(11.7)$ & $27(13.0)$ & $27(8.4)$ \\
\hline Hispanic & 1119 (22.5) & $54(26.0)$ & $100(31.0)$ \\
\hline Other & $275(5.5)$ & $11(5.3)$ & $16(5.0)$ \\
\hline \multicolumn{4}{|l|}{ Maternal age (years) } \\
\hline$\leq 24$ & 1665 (33.4) & $84(40.4)$ & $119(36.7)$ \\
\hline $25-34$ & 2633 (52.9) & $100(48.1)$ & $168(51.9)$ \\
\hline$\geq 35$ & $684(13.7)$ & $24(11.5)$ & 37 (11.4) \\
\hline \multicolumn{4}{|l|}{ Maternal education } \\
\hline$<12$ years & $836(16.9)$ & $33(15.9)$ & $58(18.2)$ \\
\hline 12 years & $1229(24.9)$ & $62(29.8)$ & $88(27.7)$ \\
\hline$>12$ years & $2877(58.2)$ & $113(54.3)$ & $172(54.1)$ \\
\hline \multicolumn{4}{|l|}{ Family income } \\
\hline$<\$ 10 \mathrm{k}$ & 794 (17.9) & $43(22.3)$ & $57(18.9)$ \\
\hline$\$ 10-\$ 50 \mathrm{~K}$ & 2069 (46.7) & $94(48.7)$ & $148(49.0)$ \\
\hline$>\$ 50 \mathrm{~K}$ & 1569 (35.4) & $56(29.0)$ & $97(32.1)$ \\
\hline \multicolumn{4}{|l|}{ Smoking (tobacco) ${ }^{\mathrm{a}}$} \\
\hline Yes & $998(20.1)$ & $50(24.0)$ & $65(20.4)$ \\
\hline No & 3958 (79.9) & $158(76.0)$ & 254 (79.6) \\
\hline \multicolumn{4}{|l|}{ Alcohol intake ${ }^{a}$} \\
\hline Yes & $2350(47.5)$ & $87(41.8)$ & $152(47.7)$ \\
\hline No & $2598(52.5)$ & $121(58.2)$ & $167(52.3)$ \\
\hline
\end{tabular}

a During pregnancy.

\section{Statistical Analysis}

Logistic regression was used to compute odds ratios (ORs) to estimate the association of maternal nutrient intakes with TLD and LLD. ORs for dietary nutrient intakes were computed for intake quartiles. Quartiles were derived from nutrient intake among control mothers, with the highest quartile being the referent group. ORs were adjusted (aORs) for maternal age $(\leq 24,25-34$, or $\geq 35$ years), education $(<12,12$, or $>12$ years), race or ethnicity (non-Hispanic White, non-Hispanic Black or African American, Hispanic, and others), energy intake (in kilocalories), body mass index (kilograms per square meter) (as a continuous variable), drinking alcohol during the periconceptional period (yes or no), and smoking tobacco during the periconceptional period (yes or no). Because nutrients examined in this study are usual components of supplements and are part of the same metabolic pathway (one-carbon metabolism), analyses were stratified based on whether or not women took supplements containing folic acid. Thus, separate analyses were conducted for women who did and those who did not take such supplements. Statistical analyses were performed using the SAS 9.1 software package (SAS Institute, Cary, NC).

\section{RESULTS}

Descriptive characteristics of mothers of case and control infants are presented in Table 1 . The proportions of male and female case infants with TLD or LLD were comparable with those of the control group. Similarly, the distribution of maternal age, education, and smoking tobacco during pregnancy or drinking alcohol during pregnancy for LLD or TLD case infants was comparable with the distribution among control infants. However, we found a substantially higher percentage $(>8 \%)$ of Hispanic infants with TLD compared to control infants.

\section{Association between Nutrient Intakes and LLD or TLD}

The proportion of women who reported taking a supplement containing folic acid during the periconceptional period was $75.8 \%$. The ORs $(95 \%$ confidence interval [CI]) associated with periconceptional use of a folic acidcontaining supplement were 0.87 (95\% CI: 0.59-1.28) for LLD and 1.10 (95\% CI: 0.82-1.47) for TLD. Results were similar after adjusting for maternal age, race or ethnicity, education, body mass index, smoking tobacco during the periconceptional period, and drinking alcohol during the periconceptional period (LLD, aOR $=1.03,95 \%$ CI: 0.68 1.56; TLD, $\mathrm{aOR}=1.18,95 \% \mathrm{CI}$ : 0.86-1.61).

Tables 2 and 3 provide aORs for LLD and TLD for maternal intakes of nutrients involved in one-carbon metabolism, stratified by periconceptional use of a folic acid-containing supplement. No nutrients were associated with LLD among women who took a supplement containing folic acid during the periconceptional period. Among women who did not take a folic acid-containing supplement, the lowest quartile compared to the highest quartile of intake for folate was associated with LLD 
Table 2

Association between Nutrient Intake during Pregnancy and the Risk for Longitudinal Limb Deficiencies among Women Who Used or Did Not Use Supplements containing Folic Acid during the Periconceptional Period

\begin{tabular}{|c|c|c|c|c|c|c|c|}
\hline & \multirow[b]{2}{*}{ Quartiles } & \multicolumn{3}{|c|}{ Users } & \multicolumn{3}{|c|}{ Nonusers } \\
\hline & & Controls, N & Cases, $\mathrm{N}$ & $\begin{array}{c}\text { Adjusted } \\
\text { OR }(95 \% C I)^{a}\end{array}$ & Controls, N & Cases, N & $\begin{array}{c}\text { Adjusted } \\
\text { OR }(95 \% \text { CI })^{\mathrm{a}}\end{array}$ \\
\hline \multirow{4}{*}{$\begin{array}{c}\text { Dietary folate, } \\
\mu \mathrm{g} \text { of DFEs }\end{array}$} & $<319.5$ & 773 & 19 & $0.85(0.40-1.82)$ & 228 & 13 & $3.86(1.08-13.78)$ \\
\hline & $319.5-471.4$ & 761 & 28 & $1.31(0.68-2.52)$ & 211 & 9 & $2.59(0.75-8.96)$ \\
\hline & 471.4-690.3 & 764 & 26 & $1.28(0.68-2.40)$ & 239 & 4 & $1.89(0.56-6.35)$ \\
\hline & $\geq 690.3$ & 707 & 20 & 1.0 & 286 & 6 & 1.0 \\
\hline \multirow[t]{4}{*}{ Vitamin $\mathrm{B}_{6}, \mathrm{mg}$} & $<1.35$ & 788 & 24 & $1.15(0.49-2.73)$ & 215 & 14 & $4.36(0.93-20.48)$ \\
\hline & $1.35-1.84$ & 790 & 27 & $1.32(0.61-2.83)$ & 212 & 3 & $1.47(0.28-7.57)$ \\
\hline & $1.84-2.60$ & 758 & 26 & $1.39(0.69-2.78)$ & 226 & 11 & 4.39 (1.19-16.12) \\
\hline & $\geq 2.60$ & 669 & 16 & 1.0 & 311 & 4 & 1.0 \\
\hline \multirow[t]{4}{*}{ Vitamin $B_{12}, \mu g$} & $\overline{<} 3.31$ & 771 & 19 & $0.78(0.35-1.71)$ & 234 & 12 & $3.84(0.93-15.86)$ \\
\hline & $3.31-4.87$ & 785 & 29 & $1.22(0.62-2.42)$ & 206 & 9 & 3.79 (1.01-14.32) \\
\hline & $4.87-7.23$ & 759 & 26 & $1.20(0.63-2.27)$ & 227 & 7 & $3.07(0.85-11.01)$ \\
\hline & $\geq 7.23$ & 690 & 19 & 1.0 & 297 & 4 & 1.0 \\
\hline \multirow[t]{4}{*}{ Riboflavin, mg } & $<1.35$ & 740 & 19 & $0.46(0.20-1.02)$ & 254 & 14 & $2.35(0.62-8.88)$ \\
\hline & $1.35-1.88$ & 791 & 33 & $0.95(0.49-1.86)$ & 204 & 6 & $1.42(0.37-5.51)$ \\
\hline & $1.88-2.57$ & 768 & 20 & $0.70(0.36-1.38)$ & 214 & 6 & $1.54(0.46-5.15)$ \\
\hline & $\geq 2.57$ & 706 & 21 & 1.0 & 292 & 6 & 1.0 \\
\hline \multirow[t]{4}{*}{ Betaine, mg } & $<47.1$ & 700 & 25 & $0.98(0.51-1.89)$ & 243 & 10 & $1.66(0.49-5.65)$ \\
\hline & $47.1-76.5$ & 756 & 22 & 0.88 (0.47-1.65) & 211 & 8 & $1.85(0.57-6.00)$ \\
\hline & $76.5-125.0$ & 757 & 24 & $1.05(0.58-1.90)$ & 197 & 9 & $2.33(0.74-7.29)$ \\
\hline & $\geq 125.0$ & 728 & 22 & 1.0 & 220 & 5 & 1.0 \\
\hline \multirow[t]{4}{*}{ Choline, mg } & $<188.2$ & 801 & 23 & $0.66(0.29-1.50)$ & 203 & 8 & $0.76(0.20-2.87)$ \\
\hline & $188.2-250.8$ & 794 & 24 & $0.74(0.36-1.53)$ & 184 & 8 & $1.30(0.42-3.98)$ \\
\hline & $250.8-343.2$ & 712 & 22 & 0.82 (0.43-1.59) & 215 & 7 & $1.02(0.34-3.03)$ \\
\hline & $\geq 343.2$ & 634 & 24 & 1.0 & 269 & 9 & 1.0 \\
\hline \multirow[t]{4}{*}{ Zinc, mg } & $<7.8$ & 789 & 26 & $0.73(0.35-1.53)$ & 227 & 9 & $1.15(0.31-4.22)$ \\
\hline & $7.8-10.5$ & 767 & 19 & $0.66(0.33-1.34)$ & 224 & 6 & $1.53(0.48-4.83)$ \\
\hline & $10.5-14.2$ & 746 & 20 & $0.68(0.36-1.29)$ & 233 & 9 & $1.49(0.51-4.36)$ \\
\hline & $\geq 14.2$ & 703 & 28 & 1.0 & 280 & 8 & 1.0 \\
\hline \multirow[t]{4}{*}{ Methionine, mg } & $<1.1$ & 779 & 30 & $0.79(0.36-1.74)$ & 241 & 13 & $0.77(0.21-2.85)$ \\
\hline & $1.1-1.4$ & 761 & 21 & $0.67(0.32-1.42)$ & 216 & 4 & $0.47(0.12-1.80)$ \\
\hline & $1.4-1.9$ & 762 & 22 & $0.82(0.42-1.62)$ & 225 & 8 & $1.21(0.40-3.61)$ \\
\hline & $\geq 1.9$ & 703 & 20 & 1.0 & 282 & 7 & 1.0 \\
\hline
\end{tabular}

Quartiles were obtained from the control population. The periconceptional period is defined as anytime from one month before through two months after conception.

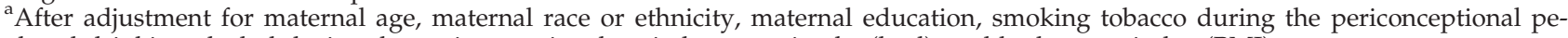
riod and drinking alcohol during the periconceptional period, energy intake (kcal), and body mass index (BMI).

OR: odds ratio; 95\% CI: 95\% confidence intervals; DFEs: dietary folate equivalents.

(aORs, 95\% CI: 3.86, 1.08-13.78). We observed a similar association for vitamin $\mathrm{B}_{6}$ intake (aORs, 95\% CI: 4.36, 0.93-20.48) and vitamin $\mathrm{B}_{12}$ (aORs, 95\% CI: 3.84, 0.9315.86), although these results did not reach statistical significance. However, the association with the second quartile for vitamin $B_{12}$ reached statistical significance (aORs $=3.79$ 95\% CI: 1.01-14.32). No other nutrients were associated with LLD among women who did not take a supplement containing folic acid.

Compared to riboflavin intakes in the highest quartile, we observed that riboflavin intakes in the lowest quartile were associated with an increased risk of TLD both for women who used a folic acid-containing supplement $(\mathrm{aOR}=1.54 ; 95 \% \mathrm{CI}: 1.00-2.37)$ and for nonsupplement users $(\mathrm{aOR}=2.94 ; 95 \% \mathrm{CI}: 1.04-8.32)$. We also observed an association between TLD and the lowest quartile of folate intake among women who used a supplement containing folic acid, although this result did not reach statistical significance $(\mathrm{aOR}=1.52 ; 95 \% \mathrm{CI}$ : 0.91-2.54). No other nutrients were associated with TLD.
When "multiple" LLD or TLD cases were excluded, dietary folate, vitamin $B_{6}$, and vitamin $B_{12}$ were no longer associated with LLD among nonusers, and the association between maternal riboflavin intake and TLD was no longer significant (not shown). The low number of isolated cases both in nonusers (40 TLD and 17 LLD) and in users (51 LLD) may explain the lack of significant association.

\section{DISCUSSION}

The present study is the first to examine the association between maternal intake of nutrients involved in one-carbon metabolism and TLD and LLD. Data indicated that lower dietary intake of certain nutrients, particularly folate and riboflavin, might be associated with an increased risk for TLD or LLD.

Our findings of a lack of association between periconceptional use of a supplement containing folic acid and TLD or LLD differed from those of previous studies (Shaw et al., 1995; Yang et al., 1997). Shaw et al. (1995) 
Table 3

Association between Nutrient Intake during Pregnancy and the Risk for Transverse Limb Deficiencies for Women Who Used or Did Not Use Supplements containing Folic Acid during the Periconceptional Period

\begin{tabular}{|c|c|c|c|c|c|c|c|}
\hline & \multirow[b]{2}{*}{ Quartiles } & \multicolumn{3}{|c|}{ Users } & \multicolumn{3}{|c|}{ Nonusers } \\
\hline & & Controls, $\mathrm{N}$ & Cases, $\mathrm{N}$ & $\begin{array}{c}\text { Adjusted } \\
\text { OR }(95 \% \text { CI })^{a}\end{array}$ & Controls, $\mathrm{N}$ & Cases, $\mathrm{N}$ & $\begin{array}{c}\text { Adjusted } \\
\text { OR }(95 \% \text { CI })^{a}\end{array}$ \\
\hline \multirow[t]{4}{*}{ Dietary folate, $\mu \mathrm{g}$ of DFEs } & $<319.5$ & 773 & 62 & $1.52(0.91-2.54)$ & 228 & 17 & $1.08(0.43-2.69)$ \\
\hline & $319.5-471.4$ & 761 & 48 & $1.05(0.64-1.72)$ & 211 & 16 & $1.00(0.43-2.33)$ \\
\hline & $471.4-690.3$ & 764 & 59 & $1.60(1.03-2.49)$ & 239 & 9 & $0.41(0.15-1.12)$ \\
\hline & $\geq 690.3$ & 707 & 40 & 1.0 & 286 & 21 & 1.0 \\
\hline \multirow[t]{4}{*}{ Vitamin $\mathrm{B}_{6}, \mathrm{mg}$} & $<1.35$ & 788 & 58 & $1.30(0.73-2.31)$ & 215 & 16 & $1.53(0.52-4.50)$ \\
\hline & $1.35-1.84$ & 790 & 57 & $1.19(0.71-2.00)$ & 212 & 16 & $1.44(0.54-3.85)$ \\
\hline & $1.84-2.60$ & 758 & 52 & $1.11(0.69-1.80)$ & 226 & 12 & $0.95(0.36-2.47)$ \\
\hline & $\geq 2.60$ & 669 & 42 & 1.0 & 311 & 19 & 1.0 \\
\hline \multirow[t]{4}{*}{ Vitamin $B_{12}, \mu g$} & $<3.31$ & 771 & 50 & $0.77(0.46-1.29)$ & 234 & 16 & $1.28(0.48-3.42)$ \\
\hline & $3.31-4.87$ & 785 & 63 & $1.01(0.64-1.58)$ & 206 & 18 & $1.58(0.66-3.82)$ \\
\hline & $4.87-7.23$ & 759 & 48 & $0.70(0.44-1.09)$ & 227 & 12 & $0.87(0.35-2.16)$ \\
\hline & $\geq 7.23$ & 690 & 48 & 1.0 & 297 & 17 & 1.0 \\
\hline \multirow[t]{4}{*}{ Riboflavin, mg } & $<1.35$ & 740 & 60 & $1.54(1.00-2.37)$ & 254 & 18 & $2.94(1.04-8.32)$ \\
\hline & $1.35-1.88$ & 791 & 56 & $1.36(0.88-2.10)$ & 204 & 16 & $2.77(0.99-4.99)$ \\
\hline & $1.88-2.57$ & 768 & 55 & $1.38(0.89-2.13)$ & 214 & 16 & $2.01(0.88-5.20)$ \\
\hline & $\geq 2.57$ & 706 & 38 & 1.0 & 292 & 13 & 1.0 \\
\hline \multirow[t]{4}{*}{ Betaine, mg } & $<47.1$ & 700 & 51 & $1.22(0.76-1.98)$ & 243 & 17 & $1.03(0.43-2.45)$ \\
\hline & $47.1-76.5$ & 756 & 54 & $1.25(0.80-1.97)$ & 211 & 12 & $0.92(0.39-2.21)$ \\
\hline & $76.5-125.0$ & 757 & 63 & 1.49 (0.97-2.29) & 197 & 13 & $1.03(0.44-2.43)$ \\
\hline & $\geq 125.0$ & 728 & 38 & 1.0 & 220 & 12 & 1.0 \\
\hline \multirow[t]{4}{*}{ Choline, mg } & $<188.2$ & 801 & 55 & $1.14(0.63-2.06)$ & 203 & 14 & $2.40(0.77-7.47)$ \\
\hline & $188.2-250.8$ & 794 & 54 & $1.10(0.64-1.85)$ & 184 & 11 & $1.81(0.62-5.24)$ \\
\hline & $250.8-343.2$ & 712 & 53 & $1.15(0.71-1.87)$ & 215 & 19 & $2.64(1.05-6.65)$ \\
\hline & $\geq 343.2$ & 634 & 44 & 1.0 & 269 & 10 & 1.0 \\
\hline \multirow[t]{4}{*}{ Zinc, mg } & $<7.8$ & 789 & 59 & $1.05(0.61-1.80)$ & 227 & 17 & $1.33(0.49-3.62)$ \\
\hline & $7.8-10.5$ & 767 & 51 & $1.01(0.62-1.66)$ & 224 & 12 & $1.28(0.51-3.19)$ \\
\hline & $10.5-14.2$ & 746 & 53 & 1.07 (0.69-1.68) & 233 & 16 & $1.01(0.42-2.44)$ \\
\hline & $\geq 14.2$ & 703 & 46 & 1.0 & 280 & 18 & 1.0 \\
\hline \multirow[t]{4}{*}{ Methionine, mg } & $<1.1$ & 779 & 58 & $1.45(0.81-2.57)$ & 241 & 20 & $1.22(0.43-3.41)$ \\
\hline & $1.1-1.4$ & 761 & 58 & $1.53(0.90-2.59)$ & 216 & 11 & $1.53(0.59-3.93)$ \\
\hline & $1.4-1.9$ & 762 & 45 & $1.06(0.63-1.78)$ & 225 & 14 & $0.45(0.14-1.42)$ \\
\hline & $\geq 1.9$ & 703 & 48 & 1.0 & 282 & 18 & 1.0 \\
\hline
\end{tabular}

Quartiles were obtained from the control population. The periconceptional period is defined as anytime from one month before through two months after conception.

${ }^{a}$ After adjustment for maternal age, maternal race/ethnicity, maternal education, smoking tobacco during the periconceptional period and drinking alcohol during the periconceptional period, energy intake (kcal), and body mass index (BMI).

OR: odds ratio; $95 \%$ CI: $95 \%$ confidence intervals; DFEs: dietary folate equivalents.

found a reduced risk for LLD with any multivitamin use and no association with TLD, whereas Yang et al. (1997) found a trend toward an association with TLD and no association with LLD. Those studies were conducted before fortification of the food supply with folic acid, and that difference might explain the inconsistency between our findings and theirs. In fact, the higher levels of folic acid among women associated with the fortification of the food supply during the current study time period (CDC, 2007) might have reduced the protective effect of folic acid through supplementation (Mosley et al., 2008), but we could not verify this possibility with the current data. Differences in the definition used for periconceptional intake were observed between our study and previous studies. However, when additional analyses using different time frames were done, that is, from 3 months before to 3 months after, from 1 month before to 3 months after, and from 1 month to 3 months before conception (not shown), similar results were obtained sug- gesting that differences in the definitions could not explain differences in results.

Although we observed no protective effect of intake of a periconceptional supplement containing folic acid, we found moderate associations with the intake of nutrients involved in one-carbon metabolism. Findings from the current study are supported by data from Sashi et al. (2001), who observed that alterations in homocysteine metabolism were associated with the occurrence of limb deficiencies. These nutrients involved in one-carbon metabolism are found in different foods. For example, riboflavin is found in dairy products and fortified foods, whereas leafy green vegetables are good sources of folate and riboflavin. Also, meat, fish, and poultry are rich sources of vitamin $\mathrm{B}_{12}$, vitamin $\mathrm{B}_{6}$, choline, and zinc. Interaction with other dietary nutrients might explain the association with nutrients from the diet but not from the supplement. Also, we do not exclude the possibility that the association might be due to other nutrients that are 
found in similar foods. Surprisingly, the association between folate and TLD was observed only among users of a supplement containing folic acid. A greater risk of the diet would be expected among nonusers. This pattern could not be explained at this time, and we cannot exclude the possibility that this association is due to chance or to other factors (dietary, environmental, or genetics) not examined in this study. Replication of our findings in other studies will be needed.

The etiologies of limb deficiencies are likely complex and heterogeneous. More importantly, it has been suggested that the etiologies of TLD and LLD likely differ (McGuirk et al., 2001). Findings from our study suggest that inadequate intake of some nutrients are associated with both TLD and LLD, although we found some differences in the nature of these nutrients. Low intake of riboflavin was associated with an increased risk for TLD, whereas no association was observed for LLD. Data from animal studies have shown that a deficiency in riboflavin early during pregnancy can cause skeletal malformations and was associated with poor fetal growth (Warkany, 1954; Kalter, 1990). Riboflavin is a cofactor of the methylenetetrahydrofolate reductase enzyme (MTHFR) and is required in the coenzyme form of flavin adenine dinucleotide. The thermolabile form of MTHFR has been shown to be more likely to dissociate from its flavin adenine dinucleotide group and thus become inactivated, suggesting an important role for riboflavin in one-carbon metabolism (Guenther et al., 1999; McNulty et al., 2002). Accordingly, riboflavin supplementation has been associated with lowered homocysteine levels, particularly among individuals homozygous for the MTHFR 677C $>$ T polymorphism (McNulty et al., 2006). However, the mechanism by which lower levels of riboflavin intake might increase the risk for limb deficiency and particularly for TLD is unknown, and we could not rule out the possibility that these associations are due to chance.

Some limitations of our study should be mentioned. The food frequency questionnaire assessed average food intake during the year before pregnancy and it is uncertain whether it reflected food intake during the periconceptional period, as food intake can change during early pregnancy (Hook, 1978; Crystal et al., 1999). In addition, food and supplement intakes were self-reported and therefore subject to potential reporting errors. Moreover, we cannot exclude the possibility that type 1 errors might have occurred because of multiple comparisons. Finally, we could not exclude the possibility of residual confounding. Despite these limitations, several strengths of the current study should be acknowledged. This is the first study to explore associations between maternal nutrient intakes and limb deficiencies. Findings from this study were based on a large case-control study and allowed us to examine associations with specific subtypes of limb deficiency rather than include them in a single case group. Additionally, the case definition was based on strict inclusion or exclusion criteria, and each case was reviewed by a clinical geneticist (R.S.O.), thus limiting the risk for case misclassification.

In conclusion, findings from this study suggest that low maternal intake of riboflavin was associated with TLD. Maternal intake of other nutrients involved in onecarbon metabolism, such as folate, might also be important for susceptibility to transverse and longitudinal limb deficiencies among offspring.

\section{ACKNOWLEDGMENTS}

This work was supported in part by the Public Health Genetics Fellowship program (to J.R.) jointly sponsored by the Centers for Disease Control and Prevention and the American Society of Human Genetics. J.R. is also the recipient of a fellowship award from the Canadian Institutes of Health and Research. We thank the California Department of Public Health Maternal Child and Adolescent Health Division for providing data for these analyses.

\section{REFERENCES}

Aberg A, Westbom L, Kallen B. 2001. Congenital malformations among infants whose mothers had gestational diabetes or preexisting diabetes. Early Hum Dev 61:85-95.

Centers for Disease Control and Prevention. 2007. Folate status in women of childbearing age, by race/ethnicity: United States, 1999-2000, 2001-2002, and 2003-2004. MMWR Morb Mortal Wkly Rep 55:13771380 .

Correa A, Gilboa SM, Besser LM, et al. 2008. Diabetes mellitus and birth defects. Am J Obstet Gynecol 199:237.e1-237.e9.

Crystal SR, Bowen DJ, Bernstein IL. 1999. Morning sickness and salt intake, food cravings, and food aversions. Physiol Behav 67:181-187.

Czeizel AE. 1993. Prevention of congenital abnormalities by periconceptional multivitamin supplementation. BMJ 306:1645-1648.

Graham JM, Miller ME, Stephan MJ, Smith DW. 1980. Limb reduction anomalies and early in utero limb compression. J Pediatr 96:10521056.

Guenther BD, Sheppard CA, Tran P, et al. 1999. The structure and properties of methylenetetrahydrofolate reductase from Escherichia coli suggest how folate ameliorates human hyperhomocysteinemia. Nat Struct Biol 6:359-365.

Holmes LB. 2002. Teratogen-induced limb defects. Am J Med Genet 112:297-303

Hook EB. 1978. Dietary cravings and aversions during pregnancy. Am J Clin Nutr 31:1355-1362

Hoyme HE, Jones KL, Van Allen MI 1982. Vascular pathogenesis of transverse limb reduction defects. J Pediatr 101:839-843.

Hunter AG. 2000. A pilot study of the possible role of familial defects in anticoagulation as a cause for terminal limb reduction malformations. Clin Genet 57:197-204.

Kalter H. 1990. Analysis of the syndrome of congenital malformations induced in genetically defined mice by acute riboflavin deficiency. Teratog Carcinog Mutagen 10:385-397.

McGuirk CK, Westgate MN, Holmes LB. 2001. Limb deficiencies in newborn infants. Pediatrics108:E64.

McNulty H, Dowey LR, Strain JJ, et al. 2006. Riboflavin lowers homocysteine in individuals homozygous for the MTHFR 677C-> T polymorphism. Circulation 113:74-80.

McNulty H, McKinley MC, Wilson B, et al. 2002. Impaired functioning of thermolabile methylenetetrahydrofolate reductase is dependent on riboflavin status: implications for riboflavin requirements. Am J Clin Nutr 76:436-441.

Moore LL, Singer MR, Bradlee ML, et al. 2000. A prospective study of the risk of congenital defects associated with maternal obesity and diabetes mellitus. Epidemiology 11:689-694.

Mosley BS, Cleves MA, Siega-Riz AM, et al. 2009. Neural tube defects and maternal folate intake among pregnancies conceived after folic acid fortification in the United States. Am J Epidemiol 169:9-17.

Shashi V, Rickheim A, Pettenati MJ, et al. 2001. Maternal homozygosity for the common MTHFR mutation as a potential risk factor for offspring with limb defects. Am J Med Genet 100:25-29.

Shaw GM, O'Malley CD, Wasserman CR 1995. Maternal periconceptional use of multivitamins and reduced risk for conotruncal heart defects and limb deficiencies among offspring. Am J Med Genet 59:536-545.

Shaw GM, Todoroff K, Schaffer DM, Selvin S. 2000. Maternal height and prepregnancy body mass index as risk factors for selected congenital anomalies. Paediatr Perinat Epidemiol 14:234-239.

U.S. Department of Agriculture Agricultural Research Service. 2006. USDA National Nutrient Database for Standard Reference, Release 19.

U.S. Department of Agriculture Agricultural Research Service. 2007. USDA National Nutrient Database for Standard Reference, Release 20.

U.S. Department of Agriculture Agricultural Research Service. 2008 USDA Database for the Choline Content of Common Foods, Release 2. 
Van Allen MI, Hoyme HE, Jones KL. 1982. Vascular pathogenesis of limb defects. I. Radial artery anatomy in radial aplasia. J Pediatr 101:832838.

Van Allen MI, Jackson JC, Knopp RH, Cone R. 1989. In utero thrombosis and neonatal gangrene in an infant of a diabetic mother. Am J Med Genet 33:323-327.

Van Allen MI, Siegel-Bartelt J, Dixon J, et al. 1992. Constriction bands and limb reduction defects in two newborns with fetal ultrasound evidence for vascular disruption. Am J Med Genet 44:598-604.

Waller DK, Shaw GM, Rasmussen SA, et al. 2007. Prepregnancy obesity as a risk factor for structural birth defects. Arch Pediatr Adolesc Med 161:745-750.

Warkany J. 1954. Disturbance of embryonic development by maternal vitamin deficiencies. J Cell Physiol Suppl 43:207-236.
Watkins ML, Rasmussen SA, Honein MA, et al. 2003. Maternal obesity and risk for birth defects. Pediatrics 111:1152-1158.

Webster WS, Lipson AH, Brown-Woodman PD. 1987. Uterine trauma and limb defects. Teratology 35:253-260.

Werler MM, Hayes C, Louik C, et al. 1999. Multivitamin supplementation and risk of birth defects. Am J Epidemiol 150:675-682.

Willett WC, Reynolds RD, Cottrell-Hoehner S, et al. 1987. Validation of a semi-quantitative food frequency questionnaire: comparison with a 1year diet record. J Am Diet Assoc 87:43-47.

Yang Q, Khoury MJ, Olney RS, Mulinare J. 1997. Does periconceptional multivitamin use reduce the risk for limb deficiency in offspring? Epidemiology 8:157-161.

Yoon PW, Rasmussen SA, Lynberg MC, et al. 2001. The National Birth Defects Prevention Study. Public Health Rep 116(Suppl 1):32-40. 